\title{
Nephrogenic Cord
}

National Cancer Institute

\section{Source}

National Cancer Institute. Nephrogenic Cord. NCI Thesaurus. Code C34219.

One of a pair of laterally positioned longitudinal masses of nephrogenic mesoderm on the urogenital ridge that is found in the early embryo, and which gives rise to the urinary system. 